Send your letters to the Editor,

British Dental Journal,

64 Wimpole Street

London

W1G 8YS

Email bdj@bda.org

Priority will be given to letters less than 500 words long.

Authors must sign the letter, which

may be edited for reasons of space.

\section{UNETHICAL AGE ASSESSMENT}

Sir, Professor Cole (BDJ 2008; 205: 581) in response to the paper by Roberts et al. (BDJ 2008; 204: E7) draws attention to what he calls the 'political hot potato' of assessing chronological age by dental $\mathrm{X}$-rays in individuals seeking asylum.

Government faces a serious practical dilemma in deciding how to manage an individual seeking asylum who claims to be a child, yet who may not have evidence from a passport or a birth certificate to document age. The assessment has major implications for these individuals, since if judged to be under the age of 18 , they will be treated as children with the full benefit of safeguarding through being children in care; if over that age they will be treated as adults. There are also financial consequences for local authorities in looking after children, and practical implications for deportation if an asylum claim is rejected.

Ministers are seeking a method which will tell with great sensitivity the precise 'age' of the person, but sadly in focussing on dental X-rays they do not have what they are seeking for the following reasons.

First, of fundamental importance is the need to understand that an X-ray can never tell the precise chronological age of the individual. All it can do is to give an assessment of the degree of maturity that $s$ /he has attained when compared with standards of normality for the population from which the individual comes. Liversidge (Ann Hum Biol 2008; 35: 294-321) has shown the very considerable range of the pace of dental development seen in normal children in England and in South Africa. We do not have reference data for the populations of children who seek asylum in the
UK who come, for example, from Eastern Europe, the Sudan, Afghanistan or Vietnam. Previous nutrition and illness may also affect the pace of dental development. In my view it is inappropriate to measure their development against standards derived from British children.

Even if we had reliable reference data from different populations, Cole has exposed the statistical and methodological weaknesses in interpreting the data presented by Roberts et al. The method cannot give a reliable probability of the range of age that the individual has achieved that will be relevant to young people at the ages for the purpose being sought.

Furthermore, I am concerned by serious ethical issues in promoting dental radiology. In today's ethical climate, the argument that 'a little bit of radiation will do no harm' cannot be sustained in the absence of any therapeutic value of the investigation to the person concerned. Whilst countries such as Australia routinely perform chest X-rays on arrivals, the result will be of considerable value in revealing a potential life-threatening illness in the individual as well as being relevant to the public health of the nation. The same arguments cannot be applied to a dental X-ray performed solely for administrative purposes.

An X-ray can only be prescribed by a medical or dental practitioner and interpreted by a radiologist after having obtained full informed consent. Many asylum seekers I have met do not speak or understand English, they may never have seen an X-ray machine before, they are often deeply traumatised and fearful of what will happen to them, and they may not be fully aware of the reasons why the X-ray is being sought let alone the implications of the result.
Clearly, if a practitioner were to subject an individual to ionising radiation solely for administrative purposes without having obtained and documented full consent and the process by which it has been obtained, then that practitioner might be guilty of serious professional misconduct.

For all these reasons, I and key professional bodies representing paediatricians, radiologists and dentists have strenuously opposed the Government's wish to recommend the routine X-raying of children for age assessment. Such assessment should be performed in Regional Assessment Centres in a holistic way led by trained social workers who can interpret the narrative of the individual's circumstance, and coupled with expert paediatric, psychological and education assessment to determine the needs of the individual. I urge medical and dental practitioners and radiologists to resist the call to perform and interpret X-rays on these highly vulnerable people. The method is inaccurate, not fit for purpose proposed, unethical and potentially unlawful.

A. Aynsley-Green, London DOI: 10.1038/sj.bdj.2009.260

\section{GDC PRODUCTS}

Sir, like all GDC registrants, I recently received a copy of the GDC booklet entitled Scope of practice. As I leafed through the booklet reading and absorbing the list of talents each registrant should possess, I was gratified to realise that such talents were almost identical to my thoughts of what each registrant could and should be able to do. That is until I read the back cover of the booklet...!

It starts very nobly with the words: 'We are committed to promoting and developing equal opportunities in all our work. We want to make sure that all 
of our products and services are accessible to everyone.'

Am I to presume from this that the GDC has given us, the dentists, a new title describing our training and competence, ie a 'product'? In much the same way as our nurses are now called 'dental care professionals' perhaps? Gee whiz, so now I can be proud to be a 'product' of the GDC, so now I can put 'P-GDC' after my name as well as LDS, BDS etc.

Now we can move on to the more exciting thrust the GDC has posed as part of the recent changes, for instance, if you would like a copy of this leaflet in large print, on audio or in a foreign language...' It seems that, on request, those who are visually impaired can read the wisdom in the booklet, as can those who cannot read English. Am I to assume from this statement that, as the booklet deals solely with the various dental disciplines, somewhere in our brave new world there is a blind dentist with a current practising certificate? If so, it would be most enlightening to find what the opinions of his patients might be, perhaps? Or even more to the point, how would such minorities know of the booklet's existence?

Now finally, as a 'product', I would like to hear how the remote possibility of a visually impaired dentist, or a dental professional with no command of the English language, could be registered? Also, for the life of me I cannot understand how this statement on the last page of the booklet can possibly gel with the GDC's forthright statement to be found on the top of each and every registrant and 'product's' certificate, that they are 'protecting patients, regulating the dental team'. Wonderful!?

Now can I have some of my $£ 400$ back please?

P. Jeavons LDS, P-GDC, Sheffield DOI: 10.1038/sj.bdj.2009.261

\section{OF USE TO ALL}

Sir, we have noted Dr Williams' complimentary review of Orthodontic radiographs: guidelines, 3rd edition (BDJ 2009; 206: 182).

However, Dr Williams is incorrect in his or her assumption that the guidelines will be 'only of interest to orthodontists'. Every practitioner has a legal responsibility to ensure that only clinically justified radiographs are taken.
As such the flow charts within the guidelines $^{1}$ should be of use to any practitioner who treats children in the mixed dentition.

\section{K. G. Isaacson, A. R. Thom}

By email

1. Isaacson K G, Thom A R, Horner K, Whaites E. Orthodontic radiographs - guidelines. $3 r d$ ed. London: British Orthodontic Society, 2008.

$$
\text { DOI: } 10.1038 / \text { sj.bdj.2009.262 }
$$

\section{PENNY IN THE PALATE}

Sir, with regard to the letter Mistaken diagnosis in the $B D J(2008 ; 205: 295)$, I remember an incident which happened in Pfarrkirchen, Germany in the 1970s while I was working a night shift in an A\&tE department in a local hospital.

The child had oedema in the palate and exactly in the centre of the swelling there was a little opening similar to a fistula. The child was not yet at walking age and remained strangely quiet during the examination. Without any anaesthesia I used a rectal fistula probe and felt a hard item at a depth of about $1 \mathrm{~cm}$. I softly moved the probe around the edges and air came through - and after a few seconds, a 1 Pfennig coin fell out of the mucous membrane. The swelling went down very quickly and the child did not have to be kept in hospital overnight. The coin appeared to have had an antiseptic effect.

H. J. Traven, Germany DOI: 10.1038/sj.bdj.2009.263

\section{RIGHTS AND RESPONSIBILITIES}

Sir, immediately prior to Christmas I was telephoned by a longstanding patient who resides in a rural area a considerable distance from my practice who was about to depart on a holiday abroad. It was quite evident from his description that without antibiotics he would find air travel unbearable and I telephoned his pharmacist to request an emergency supply.

Previously pharmacists have been willing to oblige, provided that a written prescription was posted within 24 hours. I had understood that this was a right accorded to trained dentists registered with the GDC subject to the discretion of the pharmacist.

On this occasion I was told that the pharmacist was not allowed to issue antibiotics by means of a telephoned request from a dentist under any circumstances. I asked him to check with The Royal Pharmaceutical Society, which he did, informing me that they had agreed with him. I telephoned them myself for confirmation. The GDC informed me that they were not concerned with my practice problems, being only responsible for ensuring that I was duly registered and thereafter for dealing with any aspect of my professional performance that necessitated their further consideration. Pointing out that my ability to care for a patient's needs in an emergency, such as currently, would make my appropriate performance impossible did not concern them!

My professional insurers confirmed that their understanding of the situation was the same as mine. The BDA were unaware of this exclusion affecting dentists but stated that there was nothing they could do in the circumstances.

In desperation, I tried to telephone the Chief Dental Officer. He could not be reached and a positive firewall was created to isolate him. An alternative name was 'not at his desk' nor was he on the subsequent occasions when I called.

A barrister's opinion disclosed the law to state that a retail pharmacist is only permitted to supply prescription-only medicines for human use on instruction by telephone from the following classes of clinician in emergency: medical doctors, supplementary prescribers, community practitioner nurse prescribers, nurse independent prescribers, optometrist independent prescribers, pharmacist independent prescribers, and dentists practising in the European Economic Area or Switzerland (but not those registered in the UK Dentists Register). UKregistered dentists are excluded from this long list! A nurse prescriber can obtain supplies under such circumstances but a GDC-registered dentist cannot.

This creates hazards for patients seeking remedy in emergency and denies their reasonable rights and expectations for no sensible reason. It constrains their dentist in time of need. Urgent attention must be addressed to this anomalous situation. Despite the extensive representation which we fund as a profession, no one has hitherto noted a need for appropriate steps to be taken to address this matter.

M. B. Rothschild, London DOI: 10.1038/sj.bdj.2009.264 